\title{
Assessing the condition of the Domesday Books from the visual to the molecular
}

\author{
Nancy Bell ${ }^{1}$, René Larsen ${ }^{2}$, Kate Patten ${ }^{3}$, Dorte V. P. Sommer², Michael Drakopoulos ${ }^{4}$ and Tim Wess ${ }^{5 *}$ (i)
}

\begin{abstract}
This article presents a collaborative study to determine the condition within volumes of the Great and Little Domesday Book, held in The National Archives, UK. Advances in technology in both biochemical and biophysical analysis have allowed for the first time undetectable sub milligram sampling of the five-volume Great and Little Domesday Books at nine sites in total. Visual analysis was followed by microscopic fibre assessment, hydrothermal stability (shrinkage activity), amino acid analysis and microfocus X-ray diffraction. Based on the visual examination of 887 leaves in all five volumes of the Domesday Book, 587 leaves or $66 \%$ of the leaves exhibit a degree of surface gelatinisation due in part to humidification and pressing practices carried out as part of the many re-binding campaigns carried out over the centuries. Microfibre assessment indicated the percentage of damaged fibres detected varies from 56 to 100\% in the samples taken, a correlation between the sum of oxidative sensitive amino acids and the observed damage of fibres was obtained. More than 1000 X-ray diffraction patterns collected showed a significant variation in amount of visible fibrillar collagen within each sample scan. Micro analysis performed here on corium collagen, means the results represent an average of the cross section of the structure of which the surface constitutes the smallest part. As the major part of damage is on the surface of the parchment leaves, the condition is likely to be worse than that reflected by the analytical results shown here. This evidence therefore prompted a re-think of the preservation protocols required to extend the usable life of the Domesday Book volumes. To this end, the preservation environment for the volumes is maintained at $40-45 \%$ relative humidity $(\mathrm{RH})$ significantly lower than the recommended parameter of $55 \% \mathrm{RH}$.
\end{abstract}

Keywords: Domesday Book, Damage assessment, Amino acid analysis, Fibre assessment, Shrinkage temperature, Visual assessment, X-ray diffraction

\section{Introduction}

In 1085 William the Conqueror commissioned an extensive enquiry into the landholdings of England, the first of its kind for England, with the view to raising taxes. The results of this extensive survey of landholding in England were compiled into what have come to be known as Great Domesday and Little Domesday Books, now considered to be one of the most iconic English manuscripts. We know from documentary evidence the Domesday Books provided a 'survey it is in truth a picture of the nation, and nothing less' [1]. The Domesday Books were written on calf and sheep skin, the leaves were then folded and

\footnotetext{
${ }^{*}$ Correspondence: twess@usc.edu.au

${ }^{5}$ University of the Sunshine Coast, Sippy Downs, QLD, Australia

Full list of author information is available at the end of the article
}

sewn; wooden boards were attached and were then covered with a tawed skin. The Domesday Books were considered the work horse of English court, and as a result they were frequently consulted and routinely moved to various courts around the country north and southWinchester to York, London to Windsor. No doubt the heavy use the manuscripts received contributed in part to the physical hardships the volumes suffered over the intervening years, and contributed in part to the six binding campaigns the volumes were subjected to since the quires were first sewn together after the land survey was completed in 1086.

The first re-binding was carried out in 1179 , the most recent in 1983 when the manuscript was divided into multiple volumes-three for Great Domesday and two for Little Domesday Books. At the time of the 1983 
rebinding, thorough technical analysis of the materials and techniques used to make the Domesday Books was undertaken using tools of analysis available at the time, although limited largely to visual examination since nonsampling techniques were few [2]. Over the intervening years, methods of analysis have advanced considerably and we now have a significant opportunity to understand more about the making of the Domesday Book.

The main purpose of this project was to assess the condition of Domesday using a range of techniques from extensive visual examination to the molecular chemical signature, and to use this evidence to review current preservation policies and practices relating to the Domesday Books in the collection of The National Archives, UK. At present numerous methods like Atomic Force Microscopy [3], Attenuation Total Reflection-Fourier Transform Infrared Spectroscopy [4], thermochemical methods [5, 6] are available for the study of the analysis of the deterioration of parchment. This also includes proteomics, which is useful for identification of animal species as well as chemical degradation of the collagen [7-9]. However, in this study we have chosen methods allowing us to get most information on the condition of the parchment through visual assessment and the analysis of the very limited sub milligram amount and number of samples available [10-14]. There was another factor at play, we wanted to demonstrate to conservation professionals the potential of visual examination and analytical techniques that require vanishingly small samples.

Visual examination was carried out using the naked eye and magnification of the recto and verso of each leaf. The purpose was to record surface damage such as gelatinisation, cracks, and abrasion of ink and paint surfaces. In addition, this detailed examination offered the opportunity to examine the hair follicle patterns to determine the animal species and consider whether there was a correlation between the extent of degradation and animal species. To further characterize the type and extent of surface damage, microscopic fibre assessment, hydrothermal stability (shrinkage activity), amino acid analysis and microfocus X-ray diffraction of nine selected micro samples was carried out. The second objective of the project was to use the data gathered to improve understanding of the materials and techniques used in the making of this iconic Book. This article reports the findings of the study that informed the first of the two objectives.

\section{Experimental}

A complete visual and microscopic examination of the general condition and species origin of each of the 887 manuscript leaves in five volumes of Great and Little Domesday Books was carried out following established protocols reported in the IDAP project 2005 (Improved
Damage Assessment of Parchment EU funded 5th framework Project). This included examination of surface changes such as gelatinisation manifested as a yellow fibreless glasslike structure, calcite formation in the form of a white layer, ink and pigment damage. These physical changes were documented since these are associated with the deterioration of parchment caused by environmental factors, including exposure to moisture and subsequent drying under pressure, once a common conservation treatment, but no longer considered good practice. Exposure to moisture can contribute to the formation of stiff surface layers of calcite and gelatine, which in turn can lead to surface cracking, a problem exacerbated by expansion and contraction of the parchment structure when exposed to changes in relative humidity as seen in Fig. 1. A current theory of parchment degradation suggests that hair follicle presence and density can accelerate collagen degradation [15]. The hair remains and follicle patterns were also examined in detail with the view to identifying the species of the animal skin used to make the leaves found in both Great and Little Domesday Books. Careful analysis of the physical evidence, provided here exhibits compelling informing the historical and codicological questions surrounding the Domesday Books.

In addition to the comprehensive visual assessment, four analytical techniques were performed. Approximately $0.1 \mathrm{mg}$ of parchment corium (flesh side) was taken from nine representative sites throughout Great Domesday and Little Domesday with the purposes of determining the structural integrity of the Domesday Books. The samples were taken using a scalpel to carefully shave fibres from the surface on the flesh side of the leaves to avoid contamination from the grain side and to prevent any visual loss. Visual analysis was critical as this allowed a correlation between the macroscopic surface condition

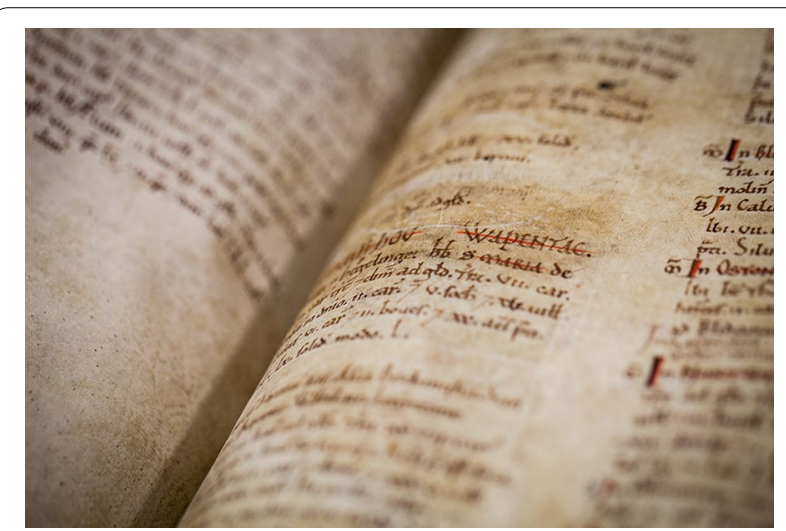

Fig. 1 An example of a leaf from the Domesday Book, the image shows the variation of surface texture 
and the measured chemical and physical condition of the selected samples. This was followed by microscopic fibre assessment and hydrothermal stability (shrinkage activity) measured by the micro hot table method (MHT), both following the IDAP protocols [16-23]. Amino acid analysis was made using high performance liquid chromatography (HPLC) to study the oxidative breakdown of the collagen [20,21, 24, 25]. Finally, X-ray diffraction (small angle scattering) was completed using a micron sized X-ray beam to assess the fibrillar structure of collagen within the samples [26-28].

\section{Fibre assessment}

The collagen fibres have a rope-like structure whereby the long-chain molecules twist alternately right and left to form long strands of micro fibrils. These in turn twist and form fibres and bundles of macroscopic fibres visible to the naked eye. When exposed to moisture and acidic conditions the fibres swell and partially twist from the rope structure to form a shape with swollen and twisted areas, creating an appearance of 'pearls on a string' [16, 19, 22]. The swollen areas are rich in charged amino acids, including Arg, His, Hyl and Lys, which are sensitive to oxidation. Under certain conditions the swelling is not reversible and the degradation or denaturation of the collagen can continue to the fibres, and in some cases the fibres may wrap up and form a two dimensional 'flat band' structure $[16,19,22]$. Under the influence of acidic conditions or oxidation, the flat bands and pearl morphological structures cleave to form small 'flat' and small 'butterfly-like' fragments. During the deterioration process the fibres may split, fray or appear cracked. In the final state, the chemical degradation is so extensive that these small fragments converted to gelatine, which at high humidity and contact with water becomes tacky or dissolves at room temperature $[16,19,22]$. The damage characteristics are normally present to various degrees in the same fibre sample and often on individual fibres, thus reflecting the complexity of the breakdown. In some cases the final deterioration products are small hard fragments that appear not to change in the presence of water even when heated.

Each fibre sample was separated on a microscope glass slide, dispersed in water and covered with a coverslip. The sample, consisting of between 10 and 15 well separated fibres, were examined in transmitted light under a microscope at a magnification of $100 \times(200 \times-400 \times$ for more detailed observation of details of a few or a single fibre). An approximation of the total number of fibres and damaged fibres were recorded. As new parchment normally contains around $20 \%$ damaged fibres due to the production, the fibre samples were graded on a values scale between 25 and 100\% (minor damage to extensive).
The extent of damage was calculated as the ratio between the measured full length and the measured length of the damaged part of each fibre in the sample observed and reported as a percentage of the total.

\section{Hydrothermal stability}

Hydrothermal stability was measured using the micro hot table method, a technique which can determine the stability of the collagen by heating fibres in water $[23,29]$. The water serves to break the relatively weak hydrogen bonds between the collagen molecules. The shrinking process normally proceeds via several intervals. In this case, the first shrinkage event observed $\left(T_{f}\right)$ and the start of the main shrinkage interval $\left(\mathrm{T}_{\mathrm{s}}\right)$, were reported. During the shrinkage process, the morphological transformation of the fibres reform, displaying localised globular features that become more pronounced and eventually lead to heavily gelatinised fibres that dissolve in the water [16].

Measurements were performed with a Mettler FP82 Hot Stage (Micro Hot Table, MHT) constructed to visually observe or record the events during heating through a microscope and thermostatically controlled through a Mettler FP90 Central Processor. A sample of around 10-20 fibres from the parchment sample was wetted with distilled water for $10 \mathrm{~min}$ on a microscope slide with a concavity. The fibres were separated in the water, dispersed well on the slide, covered completely with distilled water and a microscope cover glass, placed in MHT and heated at a rate of $2{ }^{\circ} \mathrm{C} / \mathrm{min}$. To record the shrinkage process a stereo microscope with a lamp using a magnification of around $\times 40$ equipped with an Infinity- 1 camera (Lumenera) and Studio Capture software (Studio86Designs) was used. The accuracy of the measurement of the shrinkage temperature (Ts) is $\pm 2{ }^{\circ} \mathrm{C}$. For a detailed description see references $[18,29]$.

\section{Amino acid analysis}

To gain a better understanding of the oxidative deterioration, amino acid analysis was performed by high performance liquid chromatography (HPLC). Further details of this analytical procedure is extensively reviewed in [24]. Oxidation of parchment collagen weakens the physical stability of parchment. The results from historic parchment analysed in the IDAP project concluded that the amino acids most sensitive to oxidative modifications are Arg, Hyl, Lys, Tyr and His [24].

\section{X-ray diffraction}

X-ray diffraction patterns were collected at the European Synchrotron Radiation Facility, France on beamline ID18F using a microfocus X-ray beam. The beam size at the sample was $2 \mu \mathrm{m} \times 6 \mu \mathrm{m}$ and the wavelength of the 
$\mathrm{X}$-rays was $0.086 \mathrm{~nm}$. The $\mathrm{X}$-ray diffraction patterns were collected on a CCD (charged-coupled device) camera fixed at a sample-to detector distance of $213 \mathrm{~mm}$ [28]. The samples were mounted on a capillary and aligned perpendicular to the X-ray beam. Images of the sample area to be scanned were collected using the defocused $\mathrm{X}$-ray beam in connection with an alignment camera. The sample to beam size ratio meant that scattering experiments could be recorded at over 100 unique loci in each sample.

\section{Results and discussion}

\section{Visual analysis}

Based on the visual examination of the 887 leaves, sufficient remains of hair follicle patterns were found present on a total of 188 leaves. Of these 156 leaves could be identified as originating from calf and 32 from sheep (Table 1). Interestingly, the latter was found only in Great Domesday vol. I and Little Domesday Norfolk. Moreover, the distribution of calf and sheep leaves is idiosyncratic suggesting the supply came from different parchment producers and stock readily available.

Almost all leaves exhibit a very smooth surface and an associated floppy, paper-like quality indicating extensive humidification and pressing as part of previous binding campaigns. In addition, 587 or $66 \%$ of the leaves exhibit a degree of surface gelatinisation and, where extensive, has caused some ink and pigment loss (Table 2). Although there may be a relationship between the presence of hair follicles and the formation of gelatine, the majority of leaves without hair follicles suffered damage as seen in the distribution of gelatinisation and the remains of hair and hair follicles on the surface in Great Domesday both recto and verso as illustrated in Fig. 2. Gelatine was also found in proximity to repaired areas; this coupled with extensive gelatinisation near hair follicles as well as in areas without hair follicles indicates gelatine formation is due to extensive exposure to moisture when the leaves were humidified and pressed. Within the leaves positively identified as calf and sheep, it was found the calf leaves to be more damaged in both Great Domesday 1 and Little Domesday, Norfolk Books (Table 3). This sheds new light on the long-established view that sheep is less durable than calf.

Calcite formation was observed on the surface of 137 (15.4\%) leaves; these stiff calcite layers are cracking causing damage to ink and paint layers. The presence of calcite on the surface of the leaves in the two volumes of the Great Domesday Book may be the result of treating the surface with chalk when the parchment was made.

\section{Analysis of the selected micro samples}

Tables 4 and 5 presents the results of the visual assessment, fibre assessment, hydrothermal stability

Table 1 Animal type identified by hair follicle pattern in the five volumes

\begin{tabular}{|c|c|c|c|c|c|c|}
\hline Animal type & $\begin{array}{l}\text { GD } \\
\text { Vol. I }\end{array}$ & $\begin{array}{l}\text { GD } \\
\text { Vol. II }\end{array}$ & $\begin{array}{l}\text { LD } \\
\text { Essex }\end{array}$ & LD Norfolk & LD Suffolk & Total \\
\hline Calf & $\begin{array}{l}39 \\
(18.1 \%)\end{array}$ & $\begin{array}{l}59 \\
(29.8 \%)\end{array}$ & $\begin{array}{l}12 \\
(10.3 \%)\end{array}$ & $\begin{array}{l}9 \\
(5.2 \%)\end{array}$ & $\begin{array}{l}37 \\
(20.0 \%)\end{array}$ & $\begin{array}{l}156 \\
(17.6 \%)\end{array}$ \\
\hline Sheep & $\begin{array}{l}23 \\
(10.7 \%)\end{array}$ & 0 & 0 & $\begin{array}{l}9 \\
(5.2 \%)\end{array}$ & 0 & $\begin{array}{l}32 \\
(3.6 \%)\end{array}$ \\
\hline Unknown & $\begin{array}{l}152 \\
(70.7 \%)\end{array}$ & $\begin{array}{l}139 \\
(70.2 \%)\end{array}$ & $\begin{array}{l}105 \\
(89.7 \%)\end{array}$ & $\begin{array}{l}154 \\
(89.6 \%)\end{array}$ & $\begin{array}{l}148 \\
(80.0 \%)\end{array}$ & $\begin{array}{l}698 \\
(78.7)\end{array}$ \\
\hline No. of leaves & 215 & 198 & 117 & 172 & 185 & 887 \\
\hline
\end{tabular}

Table 2 Presence of gelatine on the surface observed in the five volumes

\begin{tabular}{|c|c|c|c|c|c|c|}
\hline Gelatinisation & $\begin{array}{l}\text { GD } \\
\text { Vol. I }\end{array}$ & $\begin{array}{l}\text { GD } \\
\text { Vol. II }\end{array}$ & $\begin{array}{l}\text { LD } \\
\text { Essex }\end{array}$ & LD Norfolk & LD Suffolk & Total \\
\hline No & $\begin{array}{l}8 \\
(3.7 \%)\end{array}$ & 0 & $\begin{array}{l}12 \\
(10.3 \%)\end{array}$ & $\begin{array}{l}102 \\
(59.3 \%)\end{array}$ & $\begin{array}{l}26 \\
(14.1 \%)\end{array}$ & $\begin{array}{l}148 \\
(16.7 \%)\end{array}$ \\
\hline Some & $\begin{array}{l}29 \\
(13.5 \%)\end{array}$ & $\begin{array}{l}9 \\
(4.5 \%)\end{array}$ & $\begin{array}{l}8 \\
(6.8 \%)\end{array}$ & $\begin{array}{l}58 \\
(33.7 \%)\end{array}$ & $\begin{array}{l}40 \\
(21.6 \%)\end{array}$ & $\begin{array}{l}144 \\
(16.2 \%)\end{array}$ \\
\hline Extensive $^{a}$ & $\begin{array}{l}178 \\
(82.8 \%)\end{array}$ & $\begin{array}{l}189 \\
(95.5 \%)\end{array}$ & $\begin{array}{l}97 \\
(82.9 \%)\end{array}$ & $\begin{array}{l}12 \\
(7.0 \%)\end{array}$ & $\begin{array}{l}119 \\
(63.3 \%)\end{array}$ & $\begin{array}{l}595 \\
(67.1 \%)\end{array}$ \\
\hline No. of leaves & 215 & 198 & 117 & 172 & 185 & 887 \\
\hline
\end{tabular}

a Remark that extensive gelatinisation in this context is defined as a gelatinised surface (from small spots to the whole surface) which is cracked and have started flaking off 

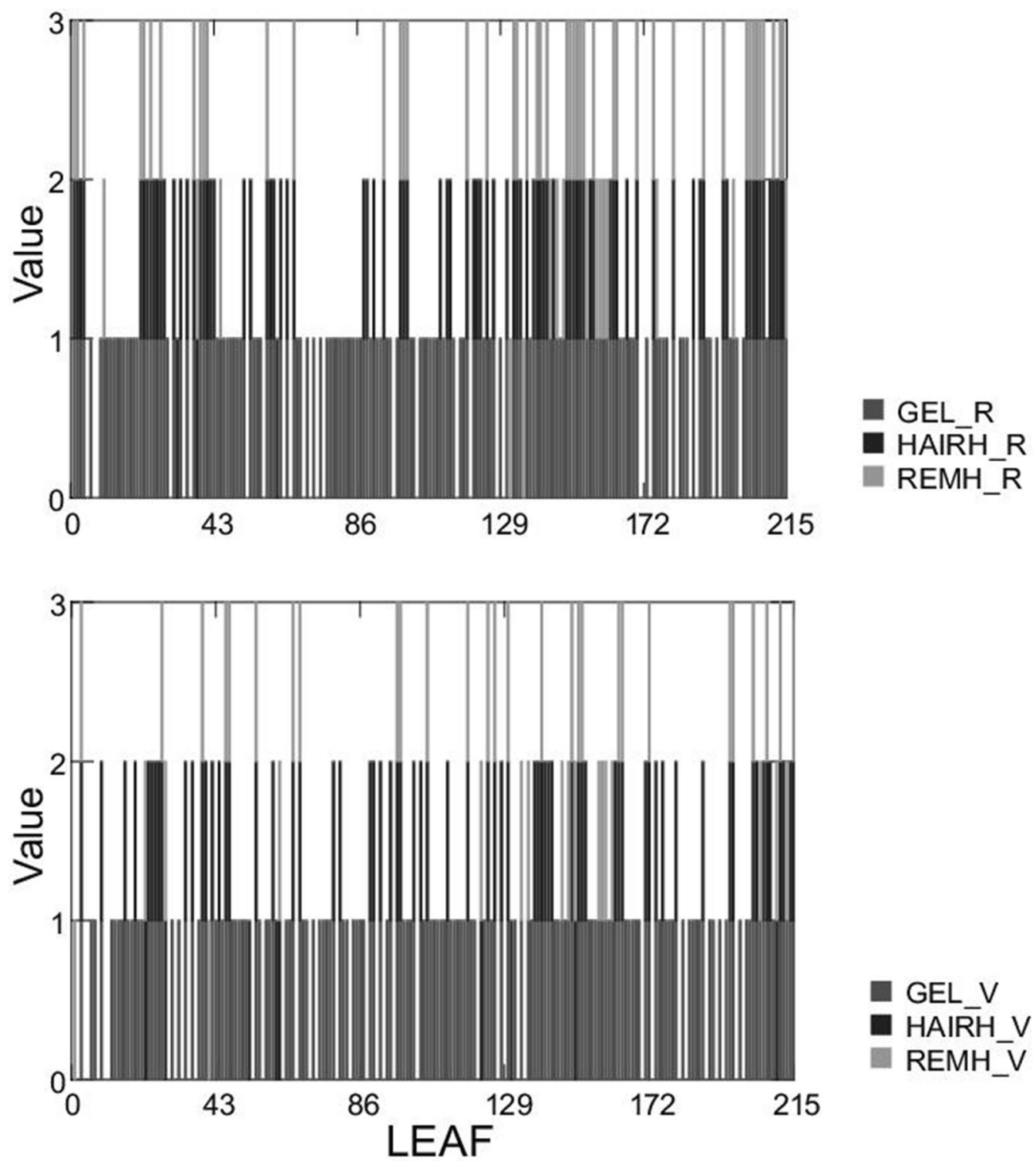

Fig. 2 Distribution of gelatinisation remains of hair and remains of hair follicles on the surface of the 215 leaves in GD1. Top: Recto side. Bottom: Verso side. Note that the distribution is only qualitative (present or not present)

measurement and amino acid analysis of eight of the selected micro samples. It is noted that sample of LD $449 \mathrm{r}$ was too small for microanalysis except for X-ray diffraction analysis.

\section{Fibre assessment}

The distribution of fibre morphologies observed in the fibre samples before heating represents the denaturation and physical damage that has already taken place in situ. The shrinkage occurring during heating represents the end of this process. A low hydrothermal activity (little and slow shrinkage) is indicative of a deteriorated structure in the form of a weak network of deformed and fragmented fibres. This may be linked with relative high shrinkage temperatures of the remaining hydrophobic and/or cross-linked parts of collagen molecules within the fibre fragments. This gives a picture of the stability of the elements in the weakened and fragmented fibres only, whereas the degree of morphological damage measured by the fibre assessment gives a picture of the physical stability and strength of the fibre network as a whole.

All fibre samples except for GD $382 \mathrm{v}$ (completely gelatinised), show various degrees of severe morphological transformation in the form of fragmentation, splitting, 
Table 3 Presence of gelatine observed at the leaves of the two volumes containing both calf and sheep

\begin{tabular}{lllc}
\hline Gelatinisation & $\begin{array}{l}\text { GD } \\
\text { Vol. I }\end{array}$ & LD Norfolk & Total \\
\hline Calf & & & \\
No & $2(5.1 \%)$ & $1(11.1 \%)$ & $3(6.2 \%)$ \\
Some & $5(12.8 \%)$ & $7(77.8 \%)$ & $12(25.0 \%)$ \\
$\quad$ Extensive & $32(82.1 \%)$ & $1(11.1 \%)$ & $33(68.8 \%)$ \\
Sheep & & & \\
No & $17(73.9 \%)$ & $4(44.4 \%)$ & $21(65.6 \%)$ \\
Some & $6(26.1 \%)$ & $5(55.6 \%)$ & $11(34.4 \%)$ \\
Extensive $^{\mathrm{a}}$ & 0 & 0 & \\
\hline
\end{tabular}

${ }^{a}$ Remark that extensive gelatinisation in this context is defined as a gelatinised surface (from small spots to the whole surface) which is cracked and have started flaking off

fraying, flattening and pearls on a string formations, as illustrated in Fig. 3a-d. As shown in Table 4, the percentage of damaged fibres detected by the fibre assessment varies from 56 to $100 \%$ corresponding to a damage category between 3 (damaged, >50\%) and 4 (extensively

Table 4 Results of visual macro and microscopic observed surface condition of leaves selected for micro sampling

\begin{tabular}{|c|c|}
\hline Volume & Visual observations \\
\hline LD 1v (Norfolk 1) & $\begin{array}{l}\text { Recto: heavy gelatine formation at lower half page } \\
\text { and in hair holes and repair parchment strip in } \\
\text { back } \\
\text { Verso: repairs on corner and outer edge. White } \\
\text { surface layer flakes off }\end{array}$ \\
\hline GD 2v (volume 1) & $\begin{array}{l}\text { Recto and verso: gelatine formation all over leave } \\
\text { surface } \\
\text { Verso: paint cracked and ink flaked off }\end{array}$ \\
\hline LD 109v (Norfolk 2) & Recto: gelatine formation \\
\hline LD 183v (Norfolk 2) & $\begin{array}{l}\text { Recto: gelatine formation probably due to with } \\
\text { repair }\end{array}$ \\
\hline GD 202v (volume 1) & $\begin{array}{l}\text { Recto and verso: loss of ink and paint } \\
\text { Recto: remains of dark and black hairs with roots } \\
\text { Verso: gelatine formation and dark brown, red- } \\
\text { brown and black hairs all over surface }\end{array}$ \\
\hline GD 203v (volume 2) & $\begin{array}{l}\text { Recto: heavy gelatine formation, heavy loss of } \\
\text { surface, ink and paint } \\
\text { Verso: like recto }\end{array}$ \\
\hline GD 382v (volume 2) & $\begin{array}{l}\text { Recto: gelatine formation all over, most at lower } \\
\text { edge } \\
\text { Verso like recto but heavier formation of gelatine, } \\
\text { loss of surface }\end{array}$ \\
\hline LD 412v (Suffolk) & $\begin{array}{l}\text { Recto: heavy gelatine formation on parchment } \\
\text { strip in back, slight gelatine formation on surface, } \\
\text { many remains of small dark hairs } \\
\text { Verso: gelatine formation }\end{array}$ \\
\hline LD 449r (Suffolk) & $\begin{array}{l}\text { Recto: heavily veined } \\
\text { Verso: heavy gelatine formation, especially lower } \\
\text { part with corner repair. The entire lower part of } \\
\text { the surface is heavily cracked }\end{array}$ \\
\hline
\end{tabular}

damaged, $>75 \%$ ). Note that the three samples (LD 1v, GD $203 \mathrm{v}$ and GD 382v) represent the leaves found to be the most damaged by visual assessment. The three samples (GD 2v, LD 109v and LD 412v), having the lowest percentage of damaged fibres also have the highest $T_{s}$ values.

\section{Hydrothermal stability}

Apart from GD 382v the samples, which dissolved in water, all have a rather high hydrothermal stability (Table 4$)$. However, the first shrinkage events $\left(\mathrm{T}_{\mathrm{f}}\right)$ of LD $412 \mathrm{v}$ and $\mathrm{LD} 1 \mathrm{v}$ takes place at $35.8^{\circ} \mathrm{C}$ and $39.6{ }^{\circ} \mathrm{C}$, respectively, indicating the ongoing deterioration of the fibres. However, in all cases there is a weak correlation in decreasing $T_{s}$ and increasing fibre damage, indicating hydrothermal stability alone does not reflect the full picture of the physical condition of the collagen fibre network $[16,19]$. The most likely explanation for a direct correlation between the results of the fibre assessment and the shrinkage temperature measurements is that the areas retained in the degraded fibres are mainly hydrophobic semi-crystalline and these have retained the hydrothermal properties that cause relatively high shrinkage temperatures.

\section{Amino acid analysis}

The oxidation of parchment collagen may weaken the physical stability of the molecules, causing a decrease in hydrothermal stability and cleavage of the fibres. This leads to an alteration of the physical structure and ultimately fragmentation. On the other hand, oxidative processes may lead to the formation of crosslinks within and between the collagen molecules, and these may act to stabilise the partly damaged and fragmented fibres resulting in higher hydrothermal stability. Analysis of historical parchment shows that the amino acids most sensitive to oxidative modifications are Tyr, His, Hyl, Lys and Arg. The percentage of the values of these amino acids is seen in Table 4. Only sample GD 203v has a sum value (7.90) placing it in the category of damage caused by oxidation. The other eight samples are characterised as exhibiting minor damage [14] indicating that even small oxidative changes in the collagen may have a detectable influence on the morphology of the collagen fibres. While there is a correlation between a decrease in these specific amino acids and $\mathrm{T}_{\mathrm{s}}$, not surprisingly the correlation is weak. Earlier studies have shown that by including other factors such as acid deterioration ( $\mathrm{pH}$ and sulphate content) in multiple regression analysis, a very accurate prediction of the $T_{s}$ of historic parchment samples could be obtained. Unfortunately, the amount of samples available in this study was too small to include measurement of $\mathrm{pH}$ and sulphate content [30]. Nevertheless 
Table 5 Results of the hydrothermal stability measurement, fibre assessment and amino acid analysis of the nine selected micro samples compared with reference values of new reference materials (standard deviations in parenthesis)

\begin{tabular}{|c|c|c|c|c|c|c|c|c|c|}
\hline Sample no. & $\mathrm{T}_{\mathrm{f}}\left({ }^{\circ} \mathrm{C}\right)$ & $\mathrm{T}_{\mathrm{s}}\left({ }^{\circ} \mathrm{C}\right)$ & Dam. fibres (\%) & Tyr & His & Hyl & Lys & Arg & Sum $^{a}$ \\
\hline LD $1 v$ & 39.6 & 53.9 & 72 & 0.32 & 0.77 & 0.41 & 2.34 & 4.34 & 8.18 \\
\hline GD 2v & 48.1 & 60.0 & 66 & 0.42 & 0.87 & 0.40 & 2.52 & 4.88 & 9.09 \\
\hline LD 109v & 50.3 & 60.8 & 67 & 0.58 & 0.49 & 0.44 & 2.23 & 4.99 & 8.73 \\
\hline LD 183v & 43.3 & 49.6 & 71 & 0.41 & 0.71 & 0.40 & 2.34 & 4.77 & 8.63 \\
\hline GD 202v & 48.2 & 54.8 & 71 & 0.40 & 0.72 & 0.37 & 2.26 & 4.85 & 8.6 \\
\hline GD 203v & 44.3 & 58.6 & 79 & 0.32 & 0.58 & 0.40 & 2.03 & 4.57 & 7.90 \\
\hline GD 382v & b & b & 100 & 0.41 & 0.76 & 0.45 & 2.43 & 4.68 & 8.73 \\
\hline LD 412v & 35.8 & 61.0 & 56 & 0.82 & 1.49 & 0.34 & 2.94 & 4.62 & 10.21 \\
\hline \multicolumn{10}{|l|}{ LD $449 r^{c}$} \\
\hline New reference & & $\approx 60$ & $\leq 30 \%$ & $0.41(0.03)$ & $1.31(0.03)$ & $0.72(0.05)$ & $2.62(0.05)$ & $5.04(0.06)$ & $10.10(0.04)$ \\
\hline
\end{tabular}

a Sum $=\Sigma$ Tyr, His, Hyl, Lys, Arg

b Dissolves by contact with water

c Sample too small for microanalysis except for X-ray diffraction analysis

the relative high sum of sensitive amino acids found for sample GD 382v and its low hydrothermal stability (dissolves when immersed in water at room temperature) indicates that acidic hydrolysis may be the main cause of deterioration.

However, a correlation between the sum of sensitive amino acids and the observed damage of fibres was obtained. Figure 4 shows a plot of the sum of these five amino acids present in samples versus the percentage of damaged fibres for seven of the samples excluding sample GD 382v, which is an outlier. The correlation coefficient $R=0.9730$ suggests that oxidative breakdown has a significant influence on the morphological characteristics of the fibres observed at the microscopic level as was the case in a study of 41 historical parchment samples [10] and an experiment with heat induced oxidation of new and historical parchment samples [21]. Moreover, it should be noted that the earlier study also showed a correlation between the oxidation of amino acids and the measured iron content in the historical parchments [30].

\section{X-ray diffraction analysis}

Microfocus X-ray diffraction allows several images to be scanned from within a small sample. An image of sample GD 382v mounted in the X-ray beam, taken using the defocused X-ray beam in connection with an alignment camera is shown in Fig. 5. 101 diffraction patterns were collected in the highlighted scan region which measured $0.4 \mu \mathrm{m} \times 0.4 \mu \mathrm{m}$.

X-ray diffraction analysis of all samples exhibited a diffraction signal corresponding to the presence of collagen fibrillar structure within the sample, this is characterised by the $65 \mathrm{~nm}$ axial meridional series of the fibre diagram. Resolution of the field of diffraction was from 0.028 to $0.17 \mathrm{~nm}^{-1}$ corresponding to the reciprocal space covering the 2nd to 12th orders of meridional diffraction. In some cases, this was very weak but visible in all samples examined. More than $1000 \mathrm{X}$-ray diffraction patterns were collected and showed a significant variation in amount of visible fibrillar collagen within each sample scan (Fig. 6). Preliminary attempts were made to determine the strength of the diffraction signal above the background, however it was recognised that the visual inspection was sufficient to show the presence of collagen molecules packed as fibrillar collagen. Samples GD 2v and GD 203v exhibited the highest level of visible fibrillar collagen as judged by the strength of the meridional diffraction signal, while samples LD 109v and LD 412v displayed the lowest level of visible fibrillar collagen signal within the scan. Sample LD 449R could not be mounted and located in the beam.

Figure 6 shows representative two-dimensional X-ray diffraction patterns for all samples that were mountable for X-ray diffraction. Sample GD 2v displayed the clearest fibrillar structure across the scan region and the highest percentage of visible fibrillar collagen. In all samples there was a presence of incomplete Debye diffraction rings indicating the presence of calcite crystallites of a similar size to or larger than the X-ray beam used [31, 32].

\section{Conclusions}

The visual assessment identified that the surface of more than half of the parchment leaves in the five volumes exhibit an extensively gelatinised surface, particularly Great Domesday Book I, Great Domesday Book II 


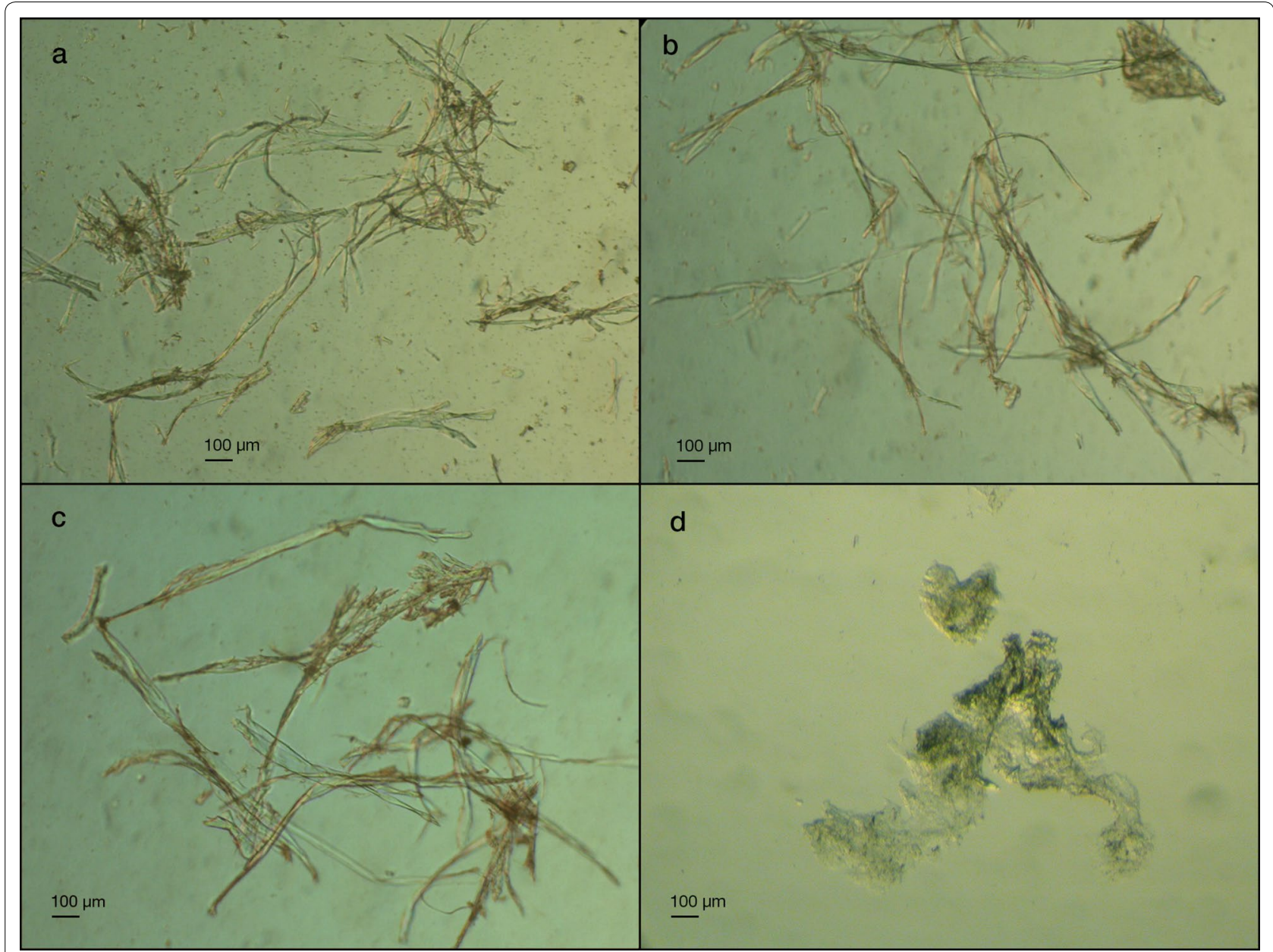

Fig. 3 a Sample LD 183v. Several long fibres, some relatively intact. Morphological damage characteristics: split, pearls on a string and a few butterfly structures and smaller fragments. Damaged fibres $=71 \% ; T_{s}=49.6^{\circ} \mathrm{C}$. b Sample LD 1v. Few long relative intact fibres. Morphological damage characteristics: split, fraying, pearls on a string and butterfly structures and several small fragments. Damaged fibres $=72 \% ; \mathrm{T}_{\mathrm{s}}=53.9^{\circ} \mathrm{C}$. $\mathbf{c}$ Short very deformed fibre fragments. Morphological damage characteristics: split, fraying, flat, and pearls on a string structures and a few very small fragments. Damaged fibres $=79 \% ; T_{s}=58.6^{\circ} \mathrm{C}$. d Sample GD 382v. Short fragments partly dissolved in water at room temperature. Morphological damage characteristics: a few very small fragments of fibre like structure. Damaged fibres $=100 \%$

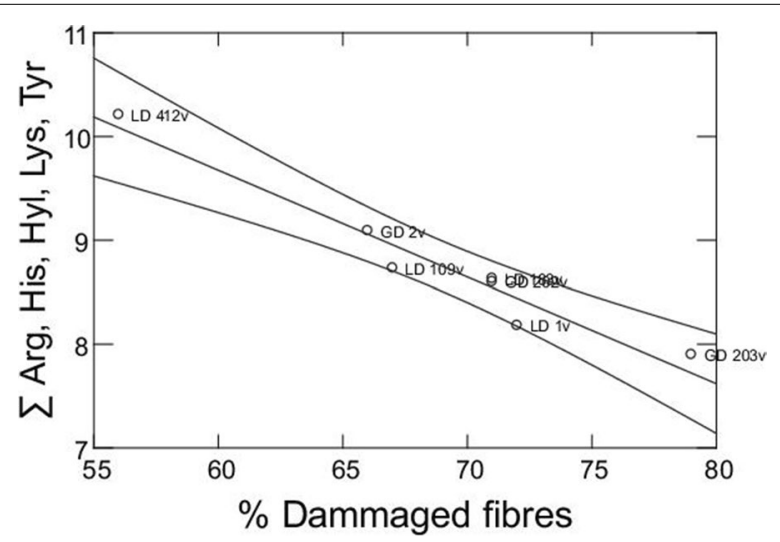

Fig. 4 The sum of the percentage values of amino acids Arg, His, Hyl, Lys and Tyr plotted against percent damage of fibres showing the 0.95 confidence interval of the regression line and Little Domesday Book Essex with 82.8\%, 91.4\% and $82.9 \%$, respectively. There is a clear relationship between the presence of hair follicles and gelatine formation; however gelatinization of the many leaves with no hair follicles, as well as the presence of heavily gelatinised repairs, indicates that repeated exposure to moisture in the past has accelerated this type of deterioration.

The results of the fibre assessment and amino acid analysis of microscopic samples on one side, and the visual examination with the fibre condition on the other, demonstrates the value of the two relatively simple diagnostic techniques. The differences and the poor correlation between the fibre assessment and the hydrothermal stability measurement shows that both methods are required to give a complete picture of the condition 


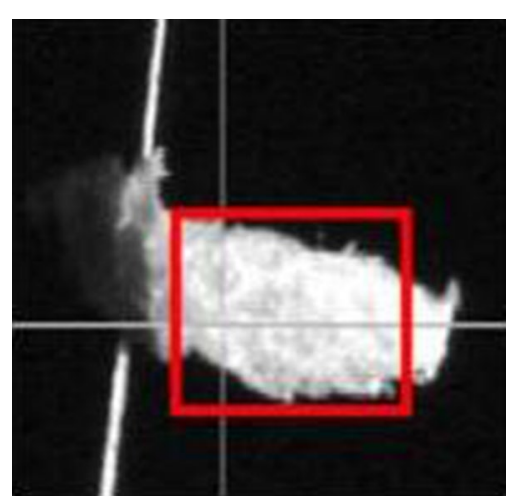

Fig. 5 An image of sample GD 382v mounted in the X-ray beam, taken using the defocused $X$-ray beam in connection with an alignment camera. 101 diffraction patterns were collected in the highlighted scan region which measured $0.4 \mu \mathrm{m} \times 0.4 \mu \mathrm{m}$

of a fibre sample. The X-ray diffraction data identified the presence of fibrillar collagen in each sample, however this signal was relatively weak compared to control samples measured at the same time. This technique therefore validates the visual analysis that the Domesday Books have undergone significant gelatinisation. The best correlation of X-ray diffraction signal corresponding to fibrillar collagen with the other complementary techniques is with hydrothermal stability (shrinkage temperature) as this demonstrates a link between the discernible diffraction and higher shrinkage temperature with all but two samples.
It is important to note that the micro analysis were performed on corium collagen, meaning the results represent an average of the cross section of the structure of which the surface constitutes the smallest part. As the major part of damage is on the surface of the parchment leaves, the condition is likely to be worse than that reflected by the analytical results shown here. There is one exception, severely damaged sample GD 382v seems to have damage extended through the full structure. The amino acid analysis of this sample indicates that this damage is probably caused by hydrolysis rather than oxidation. However, this surface deterioration is sufficient to cause the loss of text and illustrations.

The result of the assessment shows that all the five of the Domesday Books, while appearing physically sound, microscopic examination has concluded that the surface of a large number of the parchment leaves are in poor physical condition and therefore require a stable storage environment. Fluctuating relative humidity and temperature as well as the many campaigns of restoration that included various humidification techniques to reduce the undulation of the leaves, are likely to have accelerated surface gelatinisation and calcite formation, causing detectable loss of ink and pigment found in some areas of the manuscript.

The evidence emerging from this study prompted a rethink of the preservation environments required for the Domesday Books. To this end, the recommendation for improved preservation is that the Domesday volumes should be kept in an environment of $40-45 \%$ relative

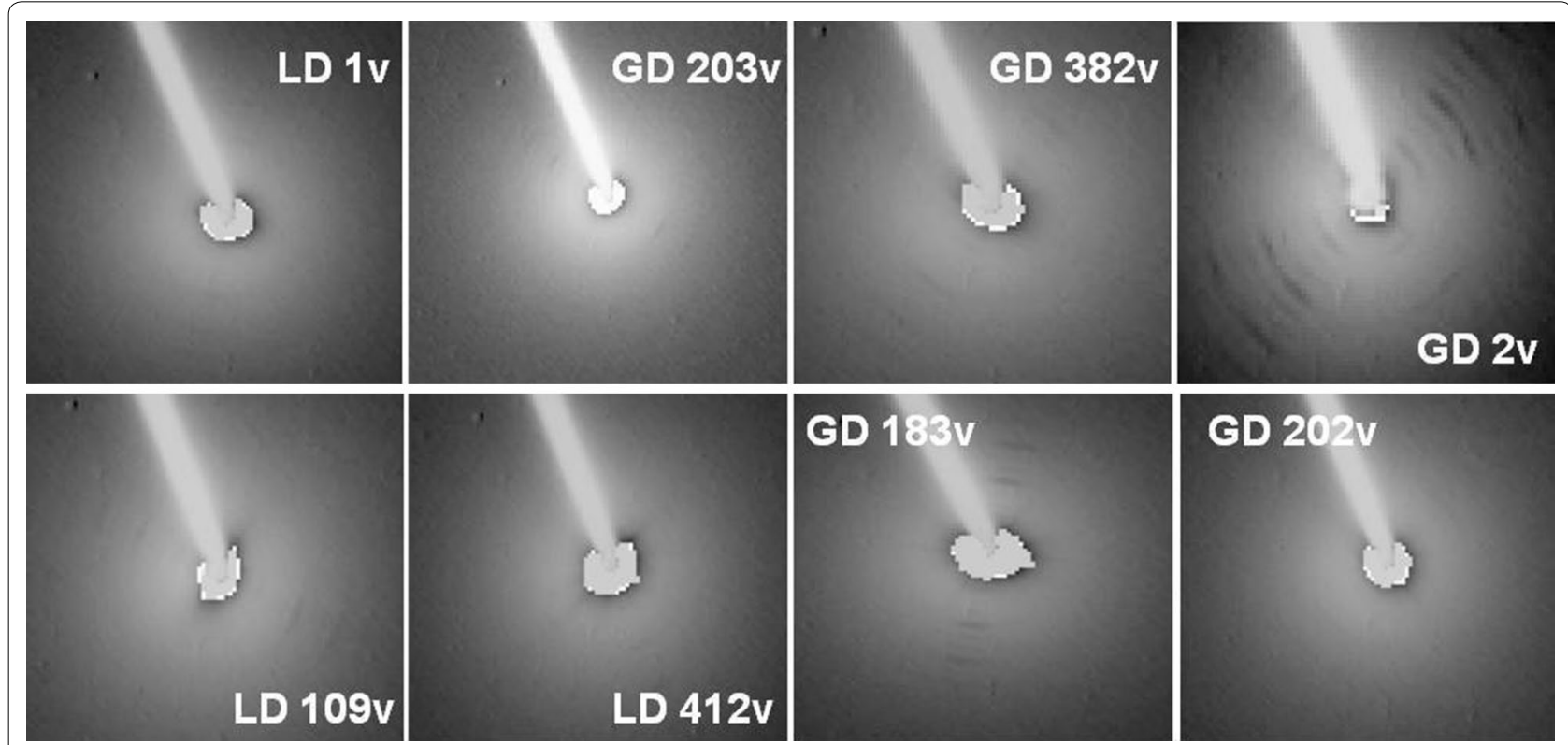

Fig. 6 Representative X-ray diffraction patterns collected from all eight samples. Each sample is identified in each individual image. The intensity of the scattering and diffraction is indicated by an inverse greyscale. Each image is optimised to show the presence of scattering from collagen 
humidity (RH) significantly lower than the recommended parameter of $55 \% \mathrm{RH}$, lower than that usually suggested for parchment artefacts.

\section{Authors' contributions}

MD, TW and KP performed the X-ray diffraction. TW and KP performed X-ray diffraction Analysis. RL and NB performed the visual assessment and sampling of Domesday. DVPS performed shrinkage measurements and amino acid analysis. All authors contributed to manuscript preparation and discussion. All authors read and approved the final manuscript.

\section{Author details}

${ }^{1}$ The National Archives and Record Administration, College Park, Maryland USA. ${ }^{2}$ Royal Danish Academy of Fine Arts, Copenhagen, Denmark. ${ }^{3}$ Cardiff University, Cardiff, UK. ${ }^{4}$ Diamond Synchrotron, Oxford, UK. ${ }^{5}$ University of the Sunshine Coast, Sippy Downs, QLD, Australia.

\section{Acknowledgements}

Thanks to The National Archives, UK for supporting this research to inform preservation protocols for Great and Little Domesday Books.

\section{Competing interests}

The authors declare that they have no competing interests.

\section{Availability of data and materials}

Not applicable.

\section{Funding}

Beamtime was Funded by the European Synchrotron Radiation Facility.

\section{Publisher's Note}

Springer Nature remains neutral with regard to jurisdictional claims in published maps and institutional affiliations.

Received: 14 May 2018 Accepted: 16 August 2018

Published online: 23 August 2018

\section{References}

1. Her Majesties Stationers Office. Domesday rebound. London: HMSO; 1953. p. 1.

2. Forde H. Domesday preserved. London: HMSO; 1986.

3. Odlyha M, Bozec L, Bartoletti A, Melita LN, Larsen R, Mühlen Axelsson K, Dahlin E, Grøntoft T, Baglioni P, Rodorico G, Chelazzi D, Bergerat R. Damage assessment of parchment at the collagen fibril level using atomic force microscopy and mechanical testing at the macro level. In: ICOM-CC 17th triennial conference. Melbourne; 2014: http://www.icom-cc. org/254/icom-cctriennial-conferences/17th-triennial-conference,-melbo urne,-australia/.

4. Boyatzis SC, Velivasaki E, Malea E. A study of the deterioration of aged parchment marked with laboratory iron gall inks using FTIR-ATR spectroscopy and micro hot table. Heritage Sci. 2016;4:13. https://doi. org/10.1186/s40494-016-0083-4.

5. Roduit B, Odlyha M. Prediction of thermal stability of fresh and aged parchment. JTherm Anal Calorim. 2006;85(1):157-64.

6. Badea E, Sommer DVP, Mühlen Axelsson K, Larsen R, Kurysheva A, Miu L, DellaGatta G. Damage ranking in historical parchments from microscopic study of fibres to collagen denaturation assessment by Micro DCS. e-Preservation Sci. 2012;9:97-109.

7. Fiddyment $\mathrm{S}$, Holsinger B, Ruzzier $\mathrm{C}$, Devine A, Binois A, Albarella $\mathrm{U}_{\text {, }}$ Fischer $\mathrm{R}$, et al. Animal origin of 13th-century uterine vellum revealed using noninvasive peptide fingerprinting. Proc Natl Acad Sci USA. 2015;112(49):15066-71

8. Brandt L, Schmidt A, Mannering U, Sarret M, Kelstrup C, Olsen J, Cappellini E. Species identification of archaeological skin objects from danish bogs: comparison between mass spectrometry-based peptide sequencing and microscopy-based methods. PLoS ONE. 2014;9(9):e106875.
9. Buckley M, Collins M, Thomas-Oates J, Wilson J. Species identification by analysis of bone collagen using matrix-assisted laser desorption/ionisation time-of-flight mass spectrometry. Rapid Commun Mass Spectrom. 2009;23(23):3843-54

10. Larsen R. Improved damage assessment of parchment. Brussels: Office for Official Publications of the European Communities; 2007. p. 113.

11. Larsen R. Microanalysis of parchment. London: Archetype Publications; 2002.

12. Možir A, Cigić IK, Marinšek M, Strlič M. Material properties of historic parchment: a reference collection survey. Stud Conserv. 2014;59(3):136-49.

13. Sommer DVP, Mühlen Axelsson K, Collins MJ, Fiddyment S, Bredal-Jørgensen J, Simonsen KP, Lauridsen CB, Larsen R. Multiple microanalyses of a sample from the Vinland Map. Archaeometry. 2017;59(2):287-301.

14. Kern MS, Pataki-Hundt A, Wouters J, Kirby DP. Accelerated ageing of parchment: investigation of a photo catalysed, low-heat approach. Restaurator. 2018;39(1):33-69.

15. Nielsen K. Visual damage assessment. In: Larsen R, editor. Improved damage assessment of parchment. Brussels: Office for Official Publications of the European Communities; 2007. p. 45-51.

16. Larsen R. Introduction to damage and damage assessment of parchment In: Larsen R, editor. Improved damage assessment of parchment. Brussels: Office for Official Publications of the European Communities; 2007. p. $17-21$.

17. Poulsen DV, Christiansen DL, Minddal K, Dahlstrom N, Larsen R. The parchment assessment programme (PDAP). In: Larsen R, editor. Improved damage assessment of parchment. Office for Official Publications of the European Communities: Brussels; 2007. p. 37-44.

18. Helpfile-Parchment Assessment Report. IDAP Project. Obtainable at the School of Conservation, The Royal Danish Academy of Fine Arts Schools of Architecture, Design and Conservation, Copenhagen.

19. Mühlen Axelsson K, Larsen R, Sommer DVP. Dimensional studies of specific microscopic fibre structures in deteriorated parchment before and during shrinkage. J Cultur Heritage. 2012;13:128-36.

20. Mühlen Axelsson K. A deeper insight to the degradation mechanisms at microscopic and molecular levels. Ph.D dissertation. The Royal Danish Academy of Fine Arts School for Architecture, Design and Conservation, School of Conservation. Denmark; 2014.

21. Mühlen Axelsson K, Larsen R, Sommer DVP, Melin R. Degradation of collagen in parchment under the influence of heat induced oxidation: preliminary study of changes at macroscopic, microscopic and molecular levels. Stud Conserv. 2016:61:46-57.

22. Axelsson Muhlen K, Larsen R, Sommer DVP, Melin R. Degradation of collagen in parchment under the influence of heat-induced oxidation: preliminary study of changes at macroscopic, microscopic, and molecular levels. Stud Conserv. 2016;61:46-57.

23. Larsen R, Vest M, Nielsen K. Determination of hydrothermal stability (shrinkage temperature) of historical leathers by the micro hot table technique. J Soc Leather Technol Chem. 1993;77:151-6.

24. Larsen R, Poulsen DVP, Minddal K, Dahlstrom N, Fazlic N. Molecular damage of parchment studied by amino acid analysis. In: Larsen $\mathrm{R}$, editor. Improved damage assessment of parchment. Brussels: Office for Official Publications of the European Communities; 2007. p. 111-4.

25. Sommer DVP, Larsen R. Detection of COL III in parchment by amino acid analysis. Amino Acids. 2016:48(1):169-81.

26. Wess TJ, Nielsen K. Analysis of collagen structure in parchment by small angle X-ray diffraction. In: Larsen R, editor. Microanalysis of parchment. London: Archetype Publications; 2002. p. 149-53.

27. Hiller JC, Kennedy CJ, Maxwell CA, Lammie D, Wess TJ. Damage to parchment collagen measured by structural and biochemical analysis. In: Larsen R, editor. Improved damage assessment of parchment. Brussels: Office for Official Publications of the European Communities; 2007. p. 99-104.

28. Kennedy CJ, Hiller JC, Lammie D, Drakopoulos M, Vest M, Cooper M Adderley WP, Wess TJ. Microfocus X-ray diffraction of historical parchment reveals variations in structural features through parchment cross sections. Nano Lett. 2004:4:1373-80.

29. Larsen R, Poulsen DVP, Minddal K, Dahlstrøm N, Fazlic N. The hydrothermal stability (shrinkage activity) of parchment measured by the micro hot table method (MHT). In: Larsen R, editor. Microanalysis of parchment. London: Archetype Publications; 2002. p. 55-62. 
30. Larsen R, Poulsen VP, Odlyha M, Nielsen K, Wouters J, Puchinger L, Brimblecombe $P$, Bowden D. The use of complementary and comparative analysis in damage assessment of parchments. In: Larsen R, editor. Microanalysis of parchment. London: Archetype Publications; 2002. p. $165-80$.
31. Somogyi A, Drakopoulos M, Vincze L, et al. ID18F: a new micro X-ray fluorescence end-station at the European Synchrotron Radiation Facility (ESRF): preliminary results. X-Ray Spectrom. 2001;30:242-52.

32. Swanson HE. Standard X-ray diffraction powder patterns. Washington: National Bureau of Standards, US Dept. of Commerce; 1955.
Submit your manuscript to a SpringerOpen ${ }^{\mathcal{O}}$ journal and benefit from:

- Convenient online submission

- Rigorous peer review

- Open access: articles freely available online

- High visibility within the field

- Retaining the copyright to your article

Submit your next manuscript at $\boldsymbol{\nabla}$ springeropen.com 